\title{
Minor Components and Oxidative Stability as Determined by DSC of Fractionated and Lipase-catalyzed Structured Rapeseed Oil
}

\author{
By M.A. Alim ${ }^{\mathrm{a}, \mathrm{c}}$, P. Wessman ${ }^{\mathrm{b}, \mathrm{d}}$ and P.C. Dutta ${ }^{\mathrm{a}, \text { * }}$ \\ ${ }^{a}$ Department of Food Science, Division of Plant Products and Food Chemistry, Uppsala BioCenter, \\ Swedish University of Agricultural Sciences, P. O. Box 7051, SE-750 07, Uppsala, Sweden \\ ${ }^{\mathrm{b}}$ AgResearch Limited, Private bag 4749, Christchurch 8140, New Zealand \\ ${ }^{\mathrm{C}}$ Department of Food Technology and Rural Industries, Bangladesh Agricultural University, \\ Mymensingh-2202, Bangladesh \\ ${ }^{d}$ Department of Microbiology, Uppsala BioCenter, Swedish University of Agricultural Sciences. \\ P. O. Box 7025, SE-750 07, Uppsala, Sweden \\ * Corresponding author: paresh.dutta@ slu.se
}

\section{RESUMEN}

Componentes menores y estabilidad a la oxidación mediante DSC de aceite de colza fraccionado y estructurado mediante catálisis con lipasa

Las grasas y aceites naturales pueden ser modificados mediante diversos métodos para preparar productos con propiedades físicas, químicas y nutricionales deseadas. El enriquecimiento y la retención de componentes lipídicos menores, la incorporación de ácido cáprico y estabilidad a la oxidación a baja temperatura de aceites de colza (RSO) fraccionado en acetona, se evaluaron en este estudio. La fracción líquida (L-RSO), la fracción sólida (S-RSO) y el RSO son transesterificados con ácido cáprico (CA) en diversas relaciones molares utilizando lipasa. Los rendimientos de las fracciones L-RSO y RSO-S fueron de 30 y $70 \mathrm{~g}$ por $100 \mathrm{~g}$, respectivamente. La fracción líquida L-RSO contenía un mayor nivel de los ácidos linoleico y linolénico, y un menor nivel de ácido oleico en comparación con la fracción sólida S-RSO. La fracción sólida S-RSO tiene mayor contenido total de esteroles que RSO y que L-RSO. En contraste, la fracción L-RSO contenía mayor contenido de tocoferoles totales que RSO y que S-RSO. La incorporación de CA fue excelente con una relación molar de 1:3. El contenido de esteroles y tocoferoles disminuyó gradualmente con un incremento de la relación molar de la incorporación de CA. La estabilidad oxidativa muestra cómo la temperatura de inicio, determinada mediante DSC, de la fracción S-RSO fue mayor en comparación con la de la L-RSO y RSO.

PALABRAS CLAVE: Aceite de colza - Calorimetría diferencial de barrido - Estabilidad oxidativa - Esteroles Reacción catalizada por lipasa - Tocoferoles.

\section{SUMMARY}

Minor Components and Oxidative Stability as Determined by DSC of Fractionated and Lipase-catalyzed Structured Rapeseed Oil

Natural fats and oils can be modified by various methods to prepare products with desired physical, chemical and nutritional properties. The enrichment and retention of the minor lipid components, the incorporation of capric acid and oxidative stability in low temperature fractionated rapeseed oil (RSO) in acetone were assessed in this study. The fractionated liquid part (L-RSO), the solid part (S-RSO) and the RSO were transesterified with capric acid (CA) at different mole ratios using lipase. The yields of L-RSO and S-RSO were 30 and $70 \mathrm{~g}$ per $100 \mathrm{~g}$, respectively. The L-RSO contained higher levels of linoleic acid and linolenic acid, and a lower level of oleic acid compared to the S-RSO. The S-RSO contained a higher amount of total sterols than the RSO and the L-RSO. In contrast, the L-RSO contained a higher amount of total tocopherols than the RSO and the S-RSO. The incorporation of CA was ideal at a mole ratio of $1: 3$. The content of sterols and tocopherols gradually decreased with an increased mole ratio for the $\mathrm{CA}$ incorporation. The oxidative stability shown as onset temperature, determined by DSC, of the S-RSO was higher compared to those of the L-RSO and RSO.

KEY-WORDS: Differential scanning calorimetry - Lipasecatalyzed reaction - Oxidative stability - Rapeseed oil Sterols - Tocopherols.

\section{INTRODUCTION}

Rapeseed is the third leading source of edible oil in the world, after palm and soybean oil. Rapeseed oil (RSO) is the most useful of all the cooking oils and it contains a significant amount of $n-3$ and n-6 fatty acids. RSO consists mostly of oleic, linoleic, linolenic, palmitic and stearic acid (Fanni et al., 2007). Refined RSO consists mainly of triacylglycerols (TAG) and some other minor components, such as phospholipids, tocopherols, tocotrienols, sterols, etc. (Shahidi and Shukla, 1996). Every vegetable oil has its own stability against oxidation, depending on its fatty acid composition and its contents of antioxidants, as well as other minor components (Nogala-Kalucka et al., 2005, Przybylski and Eskin, 2006). In addition to their health benefits, antioxidant compounds such as tocopherols enhance oxidative stability and shelf-life (Nogala-Kalucka et al., 2005, Vasanthan et al., 2007). Similarly, phytosterols are known to lower blood cholesterol levels in humans (Ellegard et al., 2005, Normen and Frohlich, 2003). Compared 
to other vegetable oils, rapeseed oil is rich in both, tocopherols and phytosterols (KamalEldin and Andersson, 1997, Phillips et al., 2002)

Fractionation is one of the most simple and commonly used methods for modifying the thermal properties of lipids. After fractionation, each fractionated part is enriched in either higher- or lower-melting TAG molecules from the original fats and oils. Solvent fractionation at low temperatures is the most efficient of the different fractionation methods. At low temperatures, solvents such as hexane, acetone, isopropyl alcohol and their mixture increase the yields of fractionated products (Hamm, 1995). The liquid part usually contains more TAG molecules with unsaturated fatty acids than the solid part (Lee and Foglia, 2001, Mayamol et al., 2004).

Structured lipids provide specific health benefits and/or impact a specific functionality of a food product (JeungHee and KiTeak, 2006). Enzymatic transesterification is a mild way to incorporate a desired acyl group at a specific position of the TAG molecules. The incorporation of medium chain fatty acids (MCFA) such as CA in RSO fractions can impart desirable benefits because of its altered physical and chemical properties such as high oxidative stability, low viscosity and melting point, and high solubility in water. MCFA in the fat molecules are hydrolyzed by lipases to free fatty acids. These fatty acids are readily absorbed in the body and transported to the liver and oxidized, thereby decreasing the deposition of these fatty acids in adipose tissue (Kim et al., 2002, Matulka et al., 2006).

A few studies on the enrichment of phytosterols and tocopherols in vegetable oil using methods such as low temperature solvent fractionation and supercritical carbon dioxide fractionation have been published (Appelqvist, 1968, Dunford et al., 2003). To our knowledge, no study has been conducted on the distribution and retention of minor lipid components such as sterols and tocopherols in the fractionated and lipase-catalyzed structured RSO. The main objectives of the present research were to study the distribution and retention of sterols and tocopherols, and to determine their stability using differential scanning calorimitry (DSC) of low-temperature fractionated and lipase-catalyzed structured RSO with CA.

\section{MATERIALS AND METHODS}

\subsection{Oil, enzyme and chemicals}

The rapeseed oil (RSO) was acquired from AAK (AarhusKarlshamn AB, Malmö, Sweden). The lipozyme RM IM (1,3-specific, produced from Mucor miehei, with a specific activity of $30 \mathrm{U} / \mathrm{g}$, and containing micro-porous ion-exchange resin), heptadecanoic acid, capric acid, acetic acid and pancreatic lipase from porcine pancreas (Type II) were obtained from Sigma-Aldrich Chemical Co. (St. Louis, MO, USA). The standard for sterols,
$5 \alpha$-cholestane, was obtained from Steraloids (Newport, RI, USA), the reference samples of tocopherols were obtained from Merck (Darmstadt, Germany) and the Tri-Sil reagent came from Pierce Chemical Co. (Rockford, IL, USA). The standard mixture of fatty acid methyl esters (FAME), F-07, was acquired from Larodan Fine Chemicals $A B$ (Malmö, Sweden). All the other chemicals and solvents came from VWR (Stockholm, Sweden), unless otherwise stated.

\subsection{Fractionation of rapeseed oil (RSO)}

$\mathrm{RSO}$ and acetone were mixed together at a ratio of $1: 5(\mathrm{v} / \mathrm{v})$ in a conical flask. The conical flask was placed in a deep freezer at a temperature of $-20^{\circ} \mathrm{C}$ for fractionation. The L-RSO was separated from the $\mathrm{S}-\mathrm{RSO}$ by decanting after $24 \mathrm{~h}$, and the acetone was evaporated completely from both parts by a rotary vacuum evaporator and a stream of nitrogen (Yu et al., 2006). The yield of L-RSO was determined gravimetrically in duplicate. Then the L-RSO and $\mathrm{S}-\mathrm{RSO}$ were taken for further use in this study.

\subsection{Incorporation of capric acid (CA) into rapeseed oil fractions}

The RSO, L-RSO and S-RSO fractions and CA were mixed together separately in a screwcapped test tube at mole ratios of $1: 1$ (881 mg: $172 \mathrm{mg}$ ), $1: 2$ (881 mg: $344 \mathrm{mg}$ ) and 1:3 (881 mg: $516 \mathrm{mg}$ ), and $3 \mathrm{~mL}$ of hexane were added to all the reaction mixtures. Lipozyme RM IM $(10 \%$ of the total weight of the substrates) was also added. The combined mixtures were incubated immediately in an orbital-shaking water bath for $24 \mathrm{~h}$ at $110 \mathrm{rpm}$ at a temperature of $65^{\circ} \mathrm{C}$. After the transesterification reaction, the lipases were removed from the reactant by passage through a $5 \mathrm{~mL}$ disposable syringe (REF 300911, BD, Franklin Lakes, NJ, USA) with a Whatman PTFE filter $(0.45 \mu \mathrm{m})$. The solvent was evaporated with nitrogen gas in the heating module $\left(50^{\circ} \mathrm{C}\right)$. One gram of reactant was weighed and dissolved in $5 \mathrm{~mL}$ of hexane. To remove the free fatty acids in each reactant, $2 \mathrm{~mL}$ of ethanol and 2-3 drops of phenolphthalein solution were added, and then the mixture was titrated with a $0.5 \mathrm{~N} \mathrm{KOH}$ solution in $20 \%$ ethanol until a pink color appeared. The upper phase was separated and dried under nitrogen gas with mild heat (Alim et al., 2008), and then the CA incorporation of the lipase-catalyzed product was analyzed by GC as described below.

\subsection{Hydrolysis by pancreatic lipase for positional fatty acid composition}

The RSO, L-RSO and S-RSO (8 mg) were taken in a test tube. Eight $\mathrm{ml}$ of Tris-HCl buffer ( $\mathrm{pH} 8.0), 2 \mathrm{~mL}$ of $0.05 \%$ bile salt in distilled water $(\mathrm{w} / \mathrm{v}), 0.8 \mathrm{~mL}$ of $2.2 \% \mathrm{CaCl}_{2}$ in distilled water (w/v) and $20 \mathrm{mg}$ of pancreatic lipase (porcine pancreatic lipase, crude type II) were mixed for hydrolysis and 
vortexed for $30 \mathrm{sec}$. Other steps were followed as described previously (Sahin et al., 2005). The mixture was incubated in a water bath at $40^{\circ} \mathrm{C}$ for $3 \mathrm{~min}$, and $1 \mathrm{~mL}$ of diethyl ether was added. The diethyl ether was evaporated under nitrogen gas. The hydrolytic products were separated on a TLC plate (silica gel 60, $20 \times 20 \mathrm{~cm}, 0.25 \mathrm{~mm}$ thickness, Merck, Eurolab AB, Stockholm, Sweden) by developing a solvent of hexane/diethyl ether/acetic acid (50/50/1, v/v/v). The band of monoacylglycerol was scraped off for methylation and analyzed by GC. After that, the percentage of fatty acid at the sn-1,3 position was calculated by the following formula: $\mathrm{Sn}-1,3(\%)=(3 \mathrm{~T}-\mathrm{sn}-2) / 2$, where $\mathrm{T}$ is the total fatty acid contents of the RSO and the liquid and solid phase of the RSO, respectively. All the analyses were conducted in duplicate and a GC analysis was performed as described below.

\subsection{Fatty acid composition}

The triacylglycerol (TAG) fractions in the RSO, L-RSO and S-RSO were separated using a thinlayer chromatography (TLC) plate (silica gel 60, $20 \times 20 \mathrm{~cm}, 0.25 \mathrm{~mm}$ thickness, Merck, Eurolab AB, Stockholm, Sweden), developed with hexane/ diethyl ether/acetic acid (85/15/1, v/v/v). The visualized band corresponding to a TAG molecule was scraped off into a screw-capped tube and dissolved in $0.5 \mathrm{ml}$ of hexane, and $3 \mathrm{~mL}$ of 0.01 $\mathrm{M} \mathrm{NaOH}$ in dry methanol were added. Fifty $\mu \mathrm{L}$ of heptadecanoic acid (C17:0, $1 \mathrm{mg} \mathrm{mL}^{-1}$ in hexane), used as an internal standard, were also added in the test tube. The test tube was closed with a stopper and vortexed for proper mixing. The sample was incubated in a water bath at $50^{\circ} \mathrm{C}$ for 30 minutes under continuous shaking. Thereafter, $2 \mathrm{ml}\left(50 \% \mathrm{NaHSO}_{4}: 25 \% \mathrm{NaCl}, 1: 1 \mathrm{v} / \mathrm{v}\right.$ in water) were added in the sample tubes and the tubes were cooled under running water. Three millilitres of water and $1 \mathrm{~mL}$ of hexane were added and vortexed vigorously (Azadmard-Damirchi and Dutta, 2008). The hexane layer was separated and the solvent was evaporated with nitrogen. Gas chromatography (GC, Chrompack CP 9001, Middelburg, The Netherlands), accompanied with auto-injection and flame-ionization detection, was used for fatty acid composition analysis. A BPX70 fused-silica capillary column (50 m ×0.22 mm, $0.25 \mu \mathrm{m}$ film thickness, SGE, Austin, TX, USA) was used for separation. The injector and detector temperatures were 240 and $280^{\circ} \mathrm{C}$, respectively. The oven temperature was $160^{\circ} \mathrm{C}$ initially, increased to $220^{\circ} \mathrm{C}$ at a rate of $2^{\circ} \mathrm{C} \mathrm{min}^{-1}$, and was then maintained at $220^{\circ} \mathrm{C}$ for 5 min. The carrier gas was helium, with nitrogen as a make-up gas, at a flow rate of $30 \mathrm{~mL} \mathrm{~min}^{-1}$. The fatty acid methyl esters (FAMEs) were identified by comparison of their retention times with a standard FAME. The peak areas were integrated by Maestro version 2.4 (Chrompack, Middelburg, The Netherlands) and reported as a percentage of the total fatty acids (Appelqvist, 1968). All the analyses were conducted in duplicate.

\subsection{Analysis of sterols by GC}

The RSO, L-RSO, S-RSO and other samples $(20 \mathrm{mg})$ were put into test tubes and $1 \mathrm{~mL}$ of $2 \mathrm{M}$ $\mathrm{KOH}$ in ethanol (95\%) was added. The tubes were placed in a boiling water bath for 10 minutes with intermittent shaking and then cooled under running water. Thereafter, $1 \mathrm{~mL}$ of water, $2 \mathrm{~mL}$ of hexane containing $20 \mu \mathrm{g}$ of $5 \alpha$-cholestane as an internal standard and $200 \mu \mathrm{L}$ of absolute ethanol were added, after which the tubes were shaken vigorously and centrifuged. The hexane layer was transferred to a small test tube and the solvent was fully evaporated under a stream of nitrogen. For derivatization, $100 \mu \mathrm{L}$ of Tri-Sil reagents were added and dispersed by brief sonication. Then the sample was incubated at $60^{\circ} \mathrm{C}$ for 45 minutes and the reagent was dispersed in the ultrasonic bath. The solvent was evaporated under a stream of nitrogen. The TMS-ether derivates of the sterols were dissolved in $500 \mu \mathrm{L}$ of hexane. A sample containing about $1 \mu \mathrm{L}$ was injected in the splitless mode into a GC model 6890 with ChemStation software, Rev. B.02.01 (Agilent Technologies, Wilmington, DE, USA), connected with a GC PAL auto sampler (CTC Analytics AG, Zwingen, Switzerland) and a flame ionization detector. A combination of two fused-silica capillary columns, a DB-5MS (length $15 \mathrm{~m}$, i.d. $0.18 \mathrm{~mm}$ and film thickness $0.18 \mu \mathrm{m}$ ) and a DB-35MS (length $10 \mu \mathrm{m}$, i.d. $0.2 \mathrm{~mm}$, and film thickness $0.33 \mu \mathrm{m})$, was used, and the columns were joined together by a universal press-fit connector. The temperatures of the detector and injector were 310 and $260^{\circ} \mathrm{C}$, respectively. The carrier gas was helium and nitrogen was used as a make-up gas at flow rates of 0.7 and $30 \mathrm{~mL} \mathrm{~min}^{-1}$, respectively. The oven temperature was initially $60^{\circ} \mathrm{C}$ for $1 \mathrm{~min}$, increased to $290^{\circ} \mathrm{C}$ at a rate of $50^{\circ} \mathrm{C}$ per min, and then maintained at $290^{\circ} \mathrm{C}$ for $5 \mathrm{~min}$, after which it was increased again by $1^{\circ} \mathrm{C}$ per min for $15 \min$ to $305^{\circ} \mathrm{C}$. All the analyses were conducted in duplicate and the quantification was performed using $5 \alpha$-cholestane as an internal standard (Appelqvist, 1968).

\subsection{Analysis of tocopherols by high-pressure liquid chromatography (HPLC)}

The quantitative tocopherol content was analyzed by HPLC. The HPLC system consisted of a 510 HPLC pump (Waters, Milford, USA) and a Rheodyne Injector with a $20 \mu \mathrm{L}$ loop, as well as a Varian 9070 fluorescence detector (Walnut Creek, CA, USA). The wavelengths of the detector were set at $294 \mathrm{~nm}$ and $320 \mathrm{~nm}$ for excitation and emission, respectively. The column was a LiChroCART 250-4 (Merck KGaA, Darmstadt, Germany), packed with Lichrosphere $100 \mathrm{NH}_{2}(5$ $\mu \mathrm{m}$ particle size) and coupled to a LiChroCART 4-4 guard column (Merck KGaA, Darmstadt, Germany). Approximately $10 \mathrm{mg}$ of each sample were dissolved in $1 \mathrm{~mL}$ of $\mathrm{n}$-heptane and $20 \mu \mathrm{L}$ were injected manually. The isocratic mobile 
phase was a mixture of n-heptane:tert-butyl methyl ether:tetrahydrofuran:methanol (79:20:0.98:0.02, $\mathrm{v} / \mathrm{v} / \mathrm{v} / \mathrm{v})$ at a flow rate of $1.0 \mathrm{~mL} \mathrm{~min}^{-1}$. Each tocopherol was quantified using an external standard method and the area of each peak was calculated by an HP 3396A integrator (HewlettPackard, Avandale, PA, USA). All the analyses were conducted in duplicate.

\subsection{Oxidative stability test by differential scanning calorimetry (DSC)}

The oxidative stability of the RSO, L-RSO and S-RSO was determined with a Perkin-Elmer Pyris Diamond differential scanning calorimeter (DSC) (Norwalk, CT). The analysis was performed under a dry compressed air purge at $40 \mathrm{~mL}$ $\mathrm{min}^{-1}$. Approximately 5-9 $\mathrm{mg}$ of each sample was enclosed in $50 \mu \mathrm{L}$ aluminium sample pans with perforated lids. The samples were scanned between 100 and $250^{\circ} \mathrm{C}$ at a heating rate of $10^{\circ} \mathrm{C} \mathrm{min}^{-1}$ per band $\left(100^{\circ} \mathrm{C} \min ^{-1}\right.$ up to $\left.100^{\circ} \mathrm{C}\right)$. The calibration was performed using indium as a reference at the sample heating rates. Four individual measurements were carried out for each sample. The thermograms were normalized for the sample weights and the oxidation onset was determined by using a trigger method; i.e. the onset was defined as the point where the heat deviated by $0.01 \mathrm{~W} / \mathrm{g}$ from the base line.

\section{RESULTS AND DISCUSSION}

\subsection{Total and positional fatty acid compositions}

Rapeseed oil (RSO) was fractionated with acetone at $-20^{\circ} \mathrm{C}$ for $24 \mathrm{~h}$ and the solid (S-RSO) and liquid (L-RSO) fractions were separated. The yield was $70 \mathrm{~g}$ per $100 \mathrm{~g}$ and $30 \mathrm{~g}$ per $100 \mathrm{~g}$ for the S-RSO and L-RSO, respectively (Table 1). The major fatty acids of the L-RSO were oleic acid (18:1), linoleic acid (18:2, $\omega-6)$ and linolenic acid $(18: 3, \omega-3)$, which constitute $59 \%, 22 \%$ and $11 \%$, respectively. On the other hand, the S-RSO contained higher amounts of palmitic acid (16:0, $5 \%$, stearic acid (18:0, 2\%) and oleic acid (18:1, $63 \%)$ than the neat RSO (5\%, $2 \%$ and $62 \%$, respectively) and the L-RSO (4\%, 1\% and 59\%, respectively). The RSO, S-RSO and L-RSO had total unsaturated fatty acid contents of $92 \%, 92 \%$ and $94 \%$, respectively, as well as total saturated fatty acid contents of $8 \%, 9 \%$ and $6 \%$, respectively. Although total unsaturated fatty acids were rather similar in all the fractions, the total polyunsaturated fatty acids (PUFA) as the sum of 18:2 and 18:3 were considerably higher in L-RSO (33\%) compared with RSO (28\%) and S-RSO (26\%) (Table 1).

The S-RSO contained higher levels of oleic acid $(18: 1,57 \%)$ at the sn-2 position than the RSO (18:1, $54 \%)$ and the L-RSO (18:1, 49\%), whereas, at the

Table 1

Fatty acid composition (\% $\%$ SD) of rapeseed oil (RSO), and fractionated solid part (S-RSO) and liquid part (L-RSO) of RSO

\begin{tabular}{|c|c|c|c|c|c|c|c|c|c|}
\hline \multirow{2}{*}{ Fatty acids } & \multicolumn{3}{|c|}{ RSO } & \multicolumn{3}{|c|}{ S-RSO } & \multicolumn{3}{|c|}{ L-RSO } \\
\hline & sn-1,3 & sn-2 & Total & sn-1,3 & sn-2 & Total & sn-1,3 & sn-2 & Total \\
\hline 16:0 & $7.3 \pm 0.12$ & $0.1 \pm 0.05$ & $4.9 \pm 0.1$ & $7.5 \pm 0.1$ & $0.1 \pm 0.1$ & $5.0 \pm 0.0$ & $6.2 \pm 0.15$ & $0.5 \pm 0.0$ & $4.3 \pm 0.1$ \\
\hline $16: 1$ & $0.3 \pm 0.0$ & $\mathrm{nd}^{\dagger}$ & $0.2 \pm 0.0$ & nd & nd & nd & $0.5 \pm 0.02$ & nd & $0.3 \pm 0.05$ \\
\hline 18:0 & $2.7 \pm 0.07$ & nd & $1.8 \pm 0.05$ & $3.2 \pm 0.05$ & nd & $2.1 \pm 0.0$ & $2.0 \pm 0.02$ & nd & $1.3 \pm 0.05$ \\
\hline $18: 1$ & $66.3 \pm 0.1$ & $54.0 \pm 0.5$ & $62.2 \pm 0.1$ & $66.8 \pm 0.05$ & $56.6 \pm 0.2$ & $63.4 \pm 0.1$ & $64.4 \pm 0.0$ & $48.5 \pm 0.3$ & $59.1 \pm 0.1$ \\
\hline $18: 2$ & $13.1 \pm 0.05$ & $32.4 \pm 0.2$ & $19.5 \pm 0.1$ & $12.3 \pm 0.05$ & $31.0 \pm 0.0$ & $18.5 \pm 0.0$ & $15.6 \pm 0.05$ & $34.8 \pm 0.2$ & $22.0 \pm 0.1$ \\
\hline $18: 3$ & $6.2 \pm 0.02$ & $13.5 \pm 0.2$ & $8.6 \pm 0.05$ & $5.3 \pm 0.05$ & $12.3 \pm 0.2$ & $7.6 \pm 0.1$ & $8.4 \pm 0.1$ & $16.2 \pm 0.1$ & $11.0 \pm 0.1$ \\
\hline $20: 0$ & $0.9 \pm 0.07$ & nd & $0.6 \pm 0.05$ & $1.2 \pm 0.0$ & nd & $0.8 \pm 0.0$ & $0.6 \pm 0.0$ & nd & $0.4 \pm 0.0$ \\
\hline $20: 1$ & $2.1 \pm 0.15$ & nd & $1.4 \pm 0.1$ & $2.4 \pm 0.07$ & nd & $1.6 \pm 0.05$ & $1.8 \pm 0.0$ & nd & $1.2 \pm 0.0$ \\
\hline 22:0 & $0.5 \pm 0.2$ & nd & $0.3 \pm 0.05$ & $0.6 \pm 0.0$ & nd & $0.4 \pm 0.0$ & $0.3 \pm 0.0$ & nd & $0.2 \pm 0.0$ \\
\hline $22: 1$ & $0.6 \pm 0.15$ & nd & $0.4 \pm 0.1$ & $0.6 \pm 0.07$ & nd & $0.4 \pm 0.05$ & $0.3 \pm 0.15$ & nd & $0.2 \pm 0.1$ \\
\hline 24:0 & $0.2 \pm 0.2$ & nd & $0.1 \pm 0.05$ & $0.3 \pm 0.0$ & nd & $0.2 \pm 0.0$ & nd & nd & nd \\
\hline$\sum \mathrm{SFA}^{\ddagger}$ & & & 7.7 & & & 8.5 & & & 6.2 \\
\hline$\sum U_{F} A^{\dagger t}$ & & & 92.3 & & & 91.5 & & & 93.8 \\
\hline$\omega-6 / \omega-3$ ratio & & & 2.27 & & & 2.43 & & & 2.0 \\
\hline $\begin{array}{l}\text { Yield } \\
\left(\mathrm{g}_{\left.100 \mathrm{~g}^{-1}\right)}\right.\end{array}$ & & & - & & & $69.7 \pm 1.2$ & & & $30.3 \pm 1.12$ \\
\hline
\end{tabular}

\footnotetext{
${ }^{\dagger}$ nd, not detected

¥ Total sum of saturated fatty acids

t† Total sum of unsaturated fatty acids
} 
sn-2 position, the L-RSO contained higher levels of linoleic acid (18:2, 35\%) and linolenic acid (18:3, 16\%) than the S-RSO (31\% and $12 \%$, respectively) and the neat RSO (32\% and 14\%, respectively). Nutritionally, the presence of a higher amount of unsaturated fatty acids at the sn-2 position is important because it is easily converted during digestion and absorbed into the body (Quinlan and Moore, 1993).

The fatty acid contents at the sn-1,3 position were oleic acid (18:1, 66\%), linoleic acid (18:2, 13\%), palmitic acid (16:0, 7\%) and linolenic acid (18:3, 6\%) for the RSO. In the case of the S-RSO and the L-RSO, the fatty acid contents at the sn-1,3 position were oleic acid (18:1, 67\% and $64 \%$, respectively), linoleic acid (18:2, $12 \%$ and 16\%, respectively), palmitic acid (16:0, $8 \%$ and $6 \%$, respectively) and linolenic acid (18:3, $5 \%$ and $8 \%$, respectively). Such changes in the fatty acid compositions at different positions lead to different physical properties such as melting point, crystallization behaviour etc. The $\omega-6 / \omega-3$ ratio of the RSO, S-RSO and L-RSO were 2.27, 2.43 and 2.0, respectively. The balance of the $\omega-6 / \omega-3$ ratio is also an important determinant for decreasing the risk of coronary heart disease with regard to both primary and secondary prevention (Simopoulos, 2002).

\subsection{Incorporation of capric acid (CA) into rapeseed oil fractions}

At different mole ratios $(1: 1,1: 2$ and $1: 3)$, CA was mixed with the fractions of RSO and the neat RSO. The combined mixtures were incubated immediately in an orbital-shaking water bath for $24 \mathrm{~h}$ at $110 \mathrm{rpm}$ at a temperature of $65^{\circ} \mathrm{C}$. The fatty acid compositions of rapeseed oil (RSO), fractionated solid (S-RSO) and liquid (L-RSO) part of RSO with capric acid (CA) incorporation at different ratios are shown in Table 2. The results for the effect of the mole ratio on the incorporation of $\mathrm{CA}$ into the fractions obtained from the RSO and into the neat $\mathrm{RSO}$ are given in Fig. 1. For all the cases, the RSO,
L-RSO and S-RSO, the highest incorporation of CA (29\%, $28 \%$ and $33 \%$, respectively) was found with a mole ratio of 1:3. In the case of S-RSO: CA, the incorporation of $\mathrm{CA}$ increased sharply from a ratio of $1: 1$ to a ratio of $1: 3$. For the case of RSO: CA and L-RSO: CA, the incorporation of CA increased sharply from a ratio of $1: 1$ to a ratio of $1: 2$, and thereafter slowly from a ratio of $1: 2$ to a ratio of $1: 3$. Therefore, from the point of view of economics and reaction efficiency, the ideal mole ratio was $1: 3$ for all the cases. A higher incorporation of conjugated linoleic acid into corn oil was observed by Cho and Lee (2003) at the mole ratio 1:3 with an immobilized lipase-catalyzed reaction.

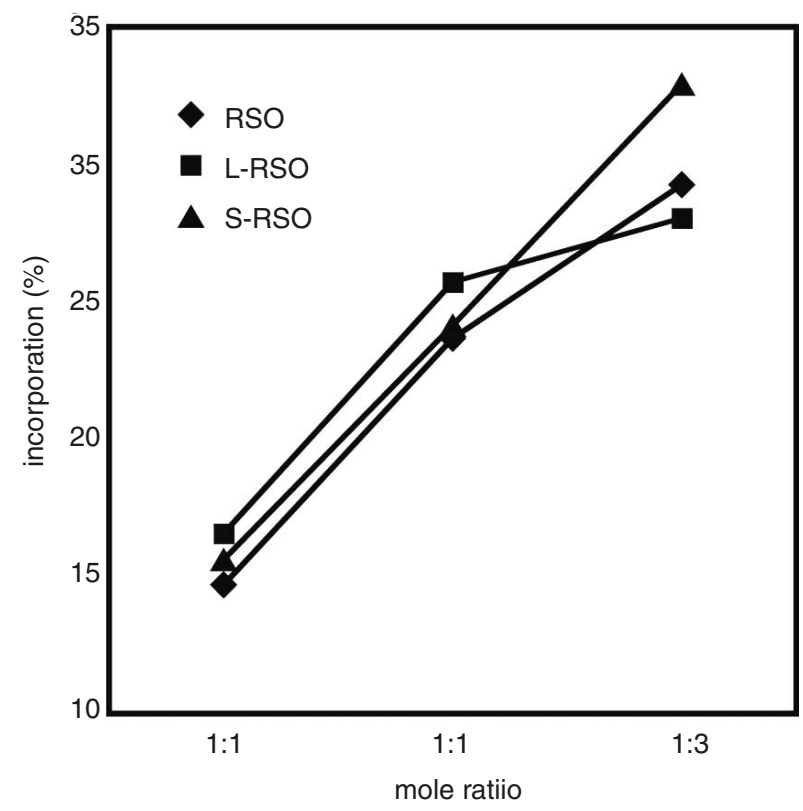

Figure 1

Effect of mole ratio on the incorporation of capric acid (CA) into the fractionated solid part (S-RSO) and liquid part (L-RSO) of rapeseed oil (RSO), and into neat rapeseed oil (RSO).

Table 2

Fatty acid compositions of rapeseed oil (RSO), fractionated solid (S-RSO) and liquid (L-RSO) parts of RSO with capric acid (CA) incorporation at different ratios

\begin{tabular}{|c|c|c|c|c|c|c|c|c|c|}
\hline \multirow{2}{*}{ FA } & \multicolumn{3}{|c|}{ RSO } & \multicolumn{3}{|c|}{ L-RSO } & \multicolumn{3}{|c|}{ S-RSO } \\
\hline & $1: 1$ & 1:2 & $1: 3$ & $1: 1$ & $1: 2$ & $1: 3$ & $1: 1$ & $1: 2$ & $1: 3$ \\
\hline 10:0 & 14.69 & 23.67 & 29.25 & 16.56 & 25.72 & 28.04 & 15.61 & 24.14 & 32.92 \\
\hline 16:0 & 3.78 & 3.01 & 2.94 & 3.53 & 2.73 & 2.44 & 4.03 & 5.31 & 2.74 \\
\hline $16: 1$ & 0.18 & 0.16 & nd & 0.19 & 0.16 & nd & 0.17 & nd & nd \\
\hline 18:0 & 1.40 & 1.14 & 1.10 & 0.96 & 0.84 & 0.78 & 1.63 & 1.62 & 1.10 \\
\hline $18: 1$ & 53.16 & 46.42 & 44.33 & 48.65 & 43.90 & 41.58 & 54.03 & 47.39 & 42.14 \\
\hline 18:2 & 17.68 & 16.78 & 15.01 & 19.39 & 17.80 & 17.68 & 16.05 & 14.14 & 14.14 \\
\hline $18: 3$ & 7.03 & 7.12 & 5.91 & 9.15 & 7.61 & 8.45 & 5.70 & 5.24 & 5.30 \\
\hline $20: 0$ & 0.47 & 0.40 & 0.41 & 0.29 & 0.25 & 0.25 & 0.59 & 0.56 & 0.40 \\
\hline $20: 1$ & 1.09 & 0.88 & 0.83 & 0.88 & 0.74 & 0.71 & 1.15 & 0.99 & 0.78 \\
\hline
\end{tabular}

nd, not detected 


\subsection{Sterol and tocopherol contents of rapeseed oil fractions}

The distribution of sterols and tocopherols during the low-temperature fractionation of RSO was assessed. The contents of sterols and tocopherols (mg per $100 \mathrm{~g}$ ) of the RSO, S-RSO and L-RSO are presented in Table 3. The major sterol in the RSO was sitosterol, followed by campesterol, brassicasterol, cholesterol, and $\Delta 5$-avenasterol. The S-RSO contained a higher amount of total sterols $(680 \mathrm{mg}$ per $100 \mathrm{~g})$ than the RSO $(632 \mathrm{mg}$ per $100 \mathrm{~g})$ and the L-RSO (541 mg per $100 \mathrm{~g}$ ). Thus, during low-temperature fractionation, cholesterol, brassicasterol and $\Delta 5$-avenasterol were enriched in the L-RSO fraction, and higher amounts of campesterol and sitosterol were observed in the S-RSO fraction. There are very few published data on the effect of temperature and solvent for the enrichment of sterols in fractionated fats and oils. It was reported that rapeseed oil contains $0.3-0.4 \%$ free sterols and 0.7 to $1.2 \%$ of esterified sterols. During the fractionation of this oil at $-80^{\circ} \mathrm{C}$ in ethyl acetate, $80 \%$ of the free sterols and $45 \%$ of the esterified sterols were enriched in the liquid fraction (Johansson and Appelqvist, 1978). In our study, we analyzed only total sterols in the fractions of the RSO $(16 \%)$ in acetone at $-20^{\circ} \mathrm{C}$. However, the content of total sterols did not follow a similar pattern. In order to optimize the enrichment of the minor components in RSO such as sterols, further studies are required.

Vegetable oils are good sources of tocopherols, which are the most important natural antioxidants. The RSO contained $26 \mathrm{mg}$ per $100 \mathrm{~g}$ of total tocopherols, which concurs with results previously published (Gunstone et al., 1994). The L-RSO contained a higher amount of total tocopherol (50 mg per $100 \mathrm{~g}$ ) than the neat RSO (26 mg per $100 \mathrm{~g})$ and the S-RSO $(20 \mathrm{mg}$ per $100 \mathrm{~g})$. All the samples contained higher amounts of $\gamma$-tocopherol than those of $\alpha$ - and $\delta$-tocopherol. Under the present experimental conditions, a higher amount of tocopherols was accumulated in the L-RSO during fractionation at $-20^{\circ} \mathrm{C}$.

\subsection{Sterol and tocopherol contents in the RSO fractions after lipase-catalyzed incorporation of capric acid (CA)}

The retention of sterols and tocopherols was monitored during the lipase-catalyzed incorporation of capric acid into the RSO fractions (Table 4). For all the cases, the total contents of sterols and tocopherols gradually decreased with increased mole ratios for the CA incorporation. After the CA was incorporated into the RSO at different mole ratios, the total sterol contents were found to be 431,384 and $373 \mathrm{mg}$ per $100 \mathrm{~g}$, respectively. Similarly, the S-RSO and L-RSO after CA incorporation at different mole ratios contained $507,442,434$ and $380,358,316 \mathrm{mg}$ per $100 \mathrm{~g}$, respectively. The total tocopherol contents of the RSO after CA incorporation at different mole ratios were 23,22 and $21 \mathrm{mg}$ per $100 \mathrm{~g}$, respectively. On the other hand, the total tocopherol contents of the S-RSO and L-RSO after CA incorporation at different mole ratios were $17,16,15$ and $38,35,31$ $\mathrm{mg}$ per $100 \mathrm{~g}$, respectively. The loss of sterol and tocopherol contents could have taken place due to a higher amount of $\mathrm{CA}$ incorporation, the enzymatic transesterification reaction or the de-acidification step, but further study is required to elucidate this.

\subsection{Oxidative stability of rapeseed oil fractions}

Oxidative stability is an important parameter for ensuring the quality of fats and oils. The results for the onset temperatures for the oxidation of the RSO, S-RSO and L-RSO for the DSC measurement are listed in Table 5. Non-isothermal

Table 3

Sterol and tocopherol contents ( $\mathrm{mg}$ per $100 \mathrm{~g} \pm \mathrm{SD}$ ) of rapeseed oil (RSO), and fractionated solid part (S-RSO) and liquid part (L-RSO) of RSO

\begin{tabular}{lccc}
\hline \multicolumn{1}{c}{$\begin{array}{c}\text { Sterol and } \\
\text { Tocopherol }\end{array}$} & RSO & S-RSO & L-RSO \\
\hline Cholesterol & $7.01 \pm 0.31$ & $6.57 \pm 0.87$ & $10.84 \pm 0.25$ \\
Brassicasterol & $59.24 \pm 1.66$ & $57.61 \pm 1.66$ & $67.41 \pm 3.79$ \\
Campesterol & $239.86 \pm 3.39$ & $263.15 \pm 9.56$ & $194.00 \pm 11.77$ \\
Sitosterol & $322.90 \pm 5.90$ & $351.01 \pm 13.12$ & $265.30 \pm 16.88$ \\
$\Delta 5$-avenasterol & $2.97 \pm 0.31$ & $1.86 \pm 0.13$ & $3.37 \pm 1.02$ \\
Total & $\mathbf{6 3 1 . 9 8}$ & $\mathbf{6 8 0 . 2 0}$ & $\mathbf{5 4 0 . 9 2}$ \\
$\alpha$-tocopherol & $3.41 \pm 0.3$ & $3.64 \pm 0.04$ & $7.57 \pm 0.08$ \\
$\gamma$-tocopherol & $19.43 \pm 0.78$ & $14.85 \pm 1.59$ & $40.33 \pm 0.68$ \\
$\delta$-tocopherol & $2.73 \pm 0.2$ & $1.43 \pm 0.03$ & $2.53 \pm 0.1$ \\
Total & $\mathbf{2 5 . 5 7}$ & $\mathbf{1 9 . 9 2}$ & $\mathbf{5 0 . 4 3}$ \\
\hline
\end{tabular}


Table 4

Sterol and tocopherol contents (mg per $\left.100 \mathrm{~g}_{ \pm} \mathrm{SD}\right)$ of rapeseed oil (RSO), and fractionated solid part (S-RSO) and liquid part (L-RSO) of RSO with capric acid (CA) incorporation at different ratios

\begin{tabular}{|c|c|c|c|c|c|c|c|c|c|}
\hline \multirow{2}{*}{$\begin{array}{l}\text { Sterols and } \\
\text { Tocopherols }\end{array}$} & \multicolumn{3}{|c|}{ RSO:CA } & \multicolumn{3}{|c|}{ S-RSO:CA } & \multicolumn{3}{|c|}{ L-RSO:CA } \\
\hline & $1: 1$ & $1: 2$ & $1: 3$ & $1: 1$ & $1: 2$ & $1: 3$ & $1: 1$ & $1: 2$ & $1: 3$ \\
\hline Cholesterol & $4.24 \pm 0.48$ & $3.97 \pm 0.09$ & $3.20 \pm 0.13$ & $4.86 \pm 0.15$ & $3.93 \pm 0.09$ & $3.94 \pm 0.12$ & $3.09 \pm 0.18$ & $3.04 \pm 0.42$ & $2.59 \pm 0.22$ \\
\hline Brassicasterol & $43.29 \pm 2.67$ & $38.16 \pm 1.67$ & $37.17 \pm 0.56$ & $44.50 \pm 0.71$ & $36.86 \pm 0.50$ & $37.87 \pm 1.82$ & $50.49 \pm 3.89$ & $47.26 \pm 0.79$ & $41.96 \pm 0.46$ \\
\hline Campesterol & $164.70 \pm 9.71$ & $147.76 \pm 5.86$ & $143.64 \pm 3.81$ & $197.18 \pm 2.83$ & $162.83 \pm 2.46$ & $167.10 \pm 9.27$ & $142.13 \pm 10.22$ & $133.02 \pm 3.42$ & $117.55 \pm 1.82$ \\
\hline Sitosterol & $215.64 \pm 12.49$ & $191.07 \pm 9.37$ & $186.36 \pm 6.08$ & $256.75 \pm 3.37$ & $235.30 \pm 4.52$ & $221.30 \pm 13.12$ & $181.80 \pm 14.28$ & $171.99 \pm 4.16$ & $152.07 \pm 3.0$ \\
\hline$\Delta 5$-avenasterol & $3.34 \pm 4.41$ & $2.60 \pm 0.16$ & $2.68 \pm 0.27$ & $3.21 \pm 0.11$ & $3.13 \pm 0.37$ & $3.43 \pm 0.27$ & $2.20 \pm 0.13$ & $2.93 \pm 0.45$ & $2.26 \pm 0.32$ \\
\hline Total & 431.21 & 383.56 & 373.05 & 506.50 & 441.95 & 433.64 & 379.71 & 358.24 & 316.43 \\
\hline$\alpha$-tocopherol & $3.80 \pm 0.45$ & $3.89 \pm 0.2$ & $3.81 \pm 0.12$ & $3.19 \pm 0.05$ & $3.17 \pm 0.21$ & $3.57 \pm 0.03$ & $6.47 \pm 0.17$ & $5.56 \pm 0.09$ & $5.73 \pm 0.13$ \\
\hline$\gamma$-tocopherol & $16.25 \pm 0.01$ & $15.45 \pm 1.09$ & $15.78 \pm 0.13$ & $13.94 \pm 0.28$ & $13.14 \pm 0.16$ & $11.09 \pm 0.15$ & $28.82 \pm 0.04$ & $26.59 \pm 0.44$ & $23.32 \pm 0.10$ \\
\hline$\delta$-tocopherol & $2.57 \pm 0.32$ & $2.23 \pm 0.24$ & $1.84 \pm 0.2$ & $n d^{\dagger}$ & nd & nd & $2.46 \pm 0.01$ & $2.75 \pm 0.1$ & $2.02 \pm 0.03$ \\
\hline Total & 22.62 & 21.57 & 21.43 & 17.13 & 16.31 & 14.66 & 37.75 & 34.90 & 31.07 \\
\hline
\end{tabular}

${ }^{\dagger}$ nd, not detected

Table 5

Onset temperatures $\left({ }^{\circ} \mathrm{C}\right)$ for oxidation of rapeseed oil (RSO), and fractionated solid part (S-RSO) and liquid part (L-RSO) of RSO*

\begin{tabular}{ccc}
\hline Sample name & $\begin{array}{c}\text { Sample size }(\mathbf{m g}) \pm \mathrm{SD} \\
\mathbf{n}=\mathbf{4}\end{array}$ & $\begin{array}{c}\text { Average Trigger (Onset) }\left({ }^{\circ} \mathbf{C}\right) \pm \mathbf{S D} \\
\mathbf{n}=\mathbf{4}\end{array}$ \\
\hline RSO & $7.12 \pm 0.67$ & $135.8 \pm 1.22$ \\
S-RSO & $7.10 \pm 1.20$ & $148.6 \pm 1.38$ \\
L-RSO & $7.10 \pm 0.63$ & $140.3 \pm 1.14$ \\
\hline
\end{tabular}

* A simple two-sided t-test assuming two-sample equal variance shows that the probability was $p=0.0025$ for RSO and L-RSO, and $p=0.00013$ for L-RSO and S-RSO

differential scanning calorimetry has previously been used to obtain kinetic parameters for the fat oxidation process (Litwinienko, 2001, Litwinienko and Musialik, 2007). Normally, different heating rates are employed to acquire enough data for a kinetic analysis of the oxidation process. As only the relative order of the oxidation stability for the different RSO-samples is of relevance for our study, one heating rate was used. A higher onset value suggests stronger oxidative stability at higher temperatures. The non-isothermal DSC records for the rapeseed oil (RSO) and the fractionated liquid part (L-RSO) and solid part (S-RSO) of the RSO are shown in Fig. 2. Actually, the oxidative stability of any vegetable oil depends on its fatty acid composition and antioxidants, mainly tocopherols (KamalEldin and Andersson, 1997, Nogala-Kalucka et al., 2005, Przybylski and Eskin, 2006). A higher average onset temperature was found for the S-RSO $\left(149^{\circ} \mathrm{C}\right)$, compared with the L-RSO $\left(140^{\circ} \mathrm{C}\right)$ and the RSO $\left(136^{\circ} \mathrm{C}\right)$. It is to be emphasized that there were lower amounts of tocopherol in the S-RSO (20 mg per $100 \mathrm{~g}$ ) than in the RSO (26 mg per $100 \mathrm{~g}$ ) and the L-RSO (50 mg per $100 \mathrm{~g})$, but the S-RSO also contained lower amounts of the sum of

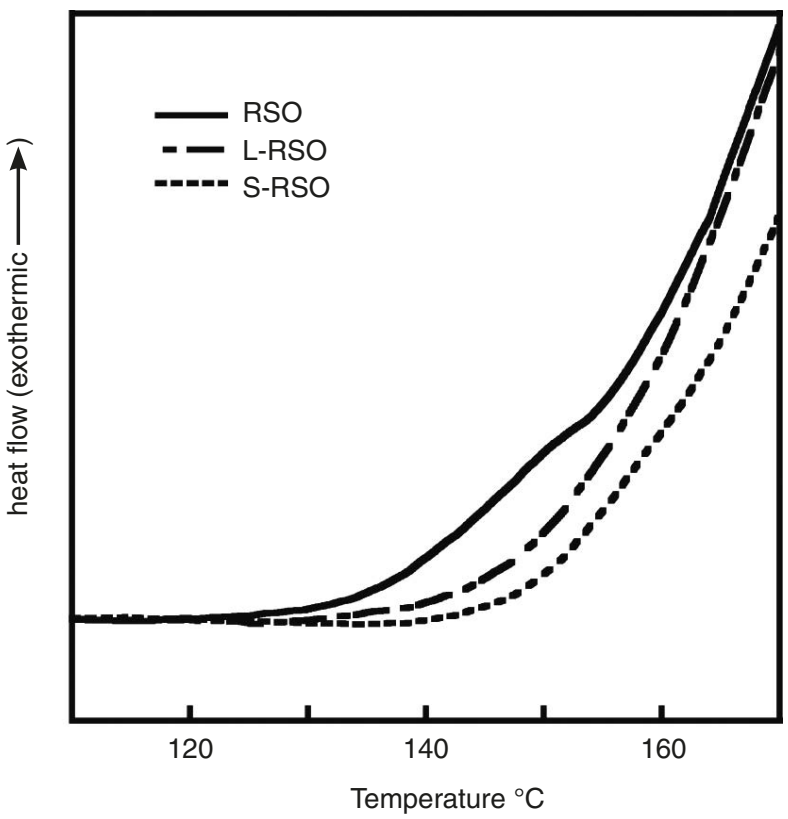

Figure 2

Representative non-isothermal differential scanning calorimetry (DSC) records for rapeseed oil (RSO), and the fractionated liquid part (L-RSO) and solid part (S-RSO) of RSO. 
$18: 2$ and $18: 3(26 \%)$ compared with RSO (28\%) and L-RSO (33\%) (Table 1), which may explain the higher onset temperature of this sample. Although L-RSO had higher levels of the sum of $18: 2$ and $18: 3$ (33\%) compared with RSO (28\%), L-RSO showed a higher onset temperature compared with RSO which was possibly due to higher and optimal tocopherol contents. The L-RSO contained higher levels of total tocopherols (50 mg per $100 \mathrm{~g}$ ) than the RSO (26 mg per $100 \mathrm{~g}$ ), resulting in an onset temperature for the L-RSO $\left(140^{\circ} \mathrm{C}\right)$ that was higher than that of the $\mathrm{RSO}\left(136^{\circ} \mathrm{C}\right)$. The antioxidants, their degree of unsaturation, and their interaction all play an important role in the oxidative stability of fats and oils (KamalEldin and Andersson, 1997, NogalaKalucka et al., 2005, Przybylski and Eskin, 2006).

\section{CONCLUSION}

Minor lipid components such as sterols, tocopherols, and fatty acids can be enriched in fats and oils by low-temperature fractionation. The fractionated oils can be used as substrates in order to prepare custom made structured oil products both for health benefits and with desired technological and functional properties which have potential applications in the food industries.

\section{REFERENCES}

Alim MA, Lee JH, Shin JA, Lee YJ, Choi MS, Akoh CC, Lee KT. 2008. Lipase-catalyzed production of solid fat stock from fractionated rice bran oil, palm stearin, and conjugated linoleic acid by response surface methodology. Food Chem. 106 712-719.

Appelqvist LÄ. 1968. Rapid methods of liquid extraction and fatty acid methyl ester preparation for seed and leaf tissue with special remarks on preventing the accumulation of lipid contaminants. Arkiv for kemi, 28, 551-570.

Azadmard-Damirchi S, Dutta PC. 2008. Stability of minor lipid components with emphasis on phytosterols during chemical interesterification of a blend of refined olive oil and palm stearin. J. Am. Oil Chem. Soc. 85, 13-21.

Cho EJ, Ee KT. 2003. Synthesis of structured lipids from corn oil and conjugated linoleic acid with immobilized lipase-catalyzed reaction. Korean J. Food Sci. Technol. 35, 797-802.

Dunford NT, Teel JA. King JW. 2003. A continuous countercurrent supercritical fluid deacidification process for phytosterol ester fortification in rice bran oil. Food Res. Int. 36, 175-181.

Ellegard L, Andersson H, Bosaeus I. 2005. Rapeseed oil, olive oil, plant sterols, and cholesterol metabolism: an ileostomy study. Eur. J. Clin Nutr. 59, 1374-1378.

Fanni J, Dubois V, Breton S, Linder M, Parmentier M. 2007. Fatty acid profiles of 80 vegetable oils with regard to their nutritional potential. Eur. J. lipid Sci. Technol. 109, 710-732.

Gunstone FD, Harwood JL, Padley FB. 1994. The lipid handbook, London, Chapman \& Hall.

Hamm W. 1995. Trends in edible oil fractionation. Trends Food Sci Technol. 6, 121-126.
Johansson A, Appelqvist LÄ. 1978. Content and composition of sterols and sterol esters in low erucicacid rapeseed (brassica-napus). Lipids, 13, 658-665.

Kamaleldin A, Andersson R. 1997. A multivariate study of the correlation between tocopherol content and fatty acid composition in vegetable oils. J. Am. Oil Chem. Soc. 74, 375-380.

Kim IH, Kim H, Lee KT, Chung SH, Ko SN. 2002. Lipasecatalyzed acidolysis of perilla oil with caprylic acid to produce structured lipids. J. Am. Oil Chem. Soc. 79, 363-367.

Lee KT, Foglia TA. 2001. Fractionation of menhaden oil and partially hydrogenated menhaden oil: characterization of triacylglycerol fractions. J. Am. Oil Chem. Soc. 78, 297-303.

Lee JeungHee L, KiTeak L. 2006. Structured lipids production, in Akoh CC (Ed.) Handbook of functional lipids, pp. 489-511. Taylor \& Francis, Boca Raton (FL, USA).

Litwinienko G. 2001. Autooxidation of unsaturated fatty acids and their esters. J. Ther. Anal. Calorim. 65, 639-646.

Litwinienko G, Musialik M. 2007. DSC study of linolenic acid autoxidation inhibited by bht, dehydrozingerone and olivetol. J. Ther. Anal. Calorim. 88, 781-785.

Matulka RA, Noguchi O, Nosaka N. 2006. Safety evaluation of a medium- and long-chain triacylglycerol oil produced from medium-chain triacylglycerols and edible vegetable oil. Food Chem. Toxicol. 44, 15301538.

Mayamol PN, Samuel T, Balachandran C, Sundaresan A, Arumughan C. 2004. Zero-trans shortening using palm stearin and rice bran oil. J. Am. Oil Chem. Soc. 81, 407-413.

Nogala-Kalucka M, Korczak J, Elmadfa I, Wagner KH. 2005. Effect of alpha- and delta-tocopherol on the oxidative stability of a mixed hydrogenated fat under frying conditions. Eur. Food Res. Technol. 221, 291-297.

Normén L, Frohlich J, Trautwein E. 2004. Role of plant sterols in cholesterol lowering, in Dutta PC (Ed.) Phytosterols as functional food components and nutraceuticals, pp. 243-315. Marcel Dekker (NY, USA).

Phillips KM, Ruggio DM, Toivo JI, Swank MA, Simpkins AH. 2002. Free and esterified sterol composition of edible oils and fats. J. Food Compos. Anal. 15, 123-142.

Przybylski R, Eskin NAM. 2006. Minor components and the stability of vegetable oils. Inform. 17, 187-189.

Quinlan P, Moore S. 1993. Modification of triacylglycerols by lipase: process technology and its application to the production of nutritionally improved fats. Inform. 4, 580-585.

Sahin N, Karaali A, Akoh, CC. 2005. Lipase-catalyzed acidolysis of tripalmitin with hazelnut oil fatty acids and stearic acid to produce human milk fat substitutes. J. Agr. Food Chem. 53, 5779-5783.

Shahidi F, Shukla, VKS. 1996. Nontriacylglycerol constituents of fats and oils. Inform. 7, 1227-1231.

Simopoulos AP. 2002. The importance of the ratio of omega-6/omega-3 essential fatty acids. Biomed pharmacother, 56, 365-379.

Vasanthan T, Zhang HY, Wettasinghe M. 2007. Enrichment of tocopherols and phytosterols in canola oil during seed germination. J. Agr. Food Chem. 55, 355-359.

Yu F, Kim SH, Kim NS, Lee JH, Bae DH, Lee KT. 2006. Composition of solvent-fractionated rice bran oil. $J$. Food Lipids. 13, 286-297. 